\title{
IMPLEMENTASI REKRUTMEN SUMBER DAYA MANUSIA DI MADRASAH ALIYAH NEGERI 2 SUMEDANG
}

\author{
Ari Prayoga* \& Arif Risnandi** \\ UIN Sunan Gunung Djati Bandung \\ *ariprayoga.spd@gmail.com \\ ** risnandiarif6@gmail.com
}

\begin{abstract}
The public relations field at Madrasah Aliyah Negeri 2 Sumedang is less informative when carrying out open employee recruitment so that job seekers are less aware of recruitment information. This study aims to reveal the implementation of human resource recruitment at Madrasah Aliyah Negeri 2 Sumedang. The research method used is qualitative. The technique of collecting data uses interviews, observation and documentation studies. The results of the study show that First, the recruitment tool at the Madrasab Aliyah Negeri 2 Sumedang uses social media advertising media using online pamphlets. The media forum was informed, namely universities to target fresh graduates. Second, organizational characteristics in madrasas that are very thick with Islamic religious nuances are very good at attracting applicants from Islamic tertiary institutions, the achievements of institutions with well-managed management of madrasas are one of the attractions for job applicants. Third, minimal compensation or salary policies make recruitment difficult. Very strict job requirements in administration in state-run madrasa aliyah with long procedures make it one of the obstacles to complaints from prospective employees.
\end{abstract}

Keywords: Implementation, Recruitment, Human resources

\begin{abstract}
Abstrak : Bidang humas di Madrasah Aliyah Negeri 2 Sumedang kurang informatif ketika melaksanakan open rekrutmen pegawai sehingga para pencari kerja kurang begitu mengetahui informasi rekrutmen. Penelitian ini bertujuan untuk mengungkap implementasi rekrutmen sumber daya manusia di Madrasah Aliyah Negeri 2 Sumedang. Metode penelitian yang digunakan adalah kualitatif. Teknik pengumpulan data menggunakan wawancara, observasi dan studi dokumentasi. Hasil penelitian menunjukkan bahwa Pertama, Perangkat rekrutmen di madrasah Aliyah Negeri 2 Sumedang menggunakan media iklan sosial media dengan memakai pamflet online. Forum media yang di informasikan yaitu perguruan tinggi untuk menyasar fresh graduate. Kedua, karakteristik organisasional di madrasah yang sangat kental dengan nuansa religi islami sangat bagus menarik pelamar dari perguruan tinggi islam, prestasi lembaga dengan predikat pengelolaan madrasah yang tertata dengan baik menjadi salah satu daya tarik bagi para pelamar kerja. Ketiga, kebijakan kompensasi atau gaji yang minim menjadikan rekrutmen agak sulit. Persyaratan pekerjaan yang sangat ketat dalam administrasi di madrasah aliyah negeri dengan prosedur yang panjang menjadikan salah satu kendala keluhan dari para calon pegawai.
\end{abstract}

Kata Kunci: Implementasi, rekrutmen, sumber daya manusia.

Manazhim : Jurnal Manajemen dan Ilmu Pendidikan

Volume 1, Nomor 2, Agustus 2019; 61-71

https://ejournal.stitpn.ac.id/index.php/manazhim 


\section{PENDAHULUAN}

Fungsi operasional dalam manajemen sumber daya manusia yang pertama yaitu mendapatkan jumlah serta jenis pegawai yang tepat untuk pencapaian tujuan organisasi. Fungsi tersebut menyangkut penentuan kebutuhan ketenagakerjaan, rekrutmen, seleksi dan penempatannya. Menentukan need assessment calon tenaga kerja bersangkutan dengan mutu maupun kuantitasnya. Seleksi dan penempatan bersangkutan dengan memilih dan menarik tenaga kerja, pembahasan tentang formulir lamaran, tes psikologi dan agenda wawancara ${ }^{1}$.

Setelah sebuah lembaga memiliki gambaran terkait hasil analisis dan rancang pekerjaan yang sesuai dengan kebutuhan serta tujuan organisasi, maka tugas bidang sumber daya manusia yaitu mengisi posisi jabatan dengan sumber daya manusia yang sesuai dan memiliki kompetensi yang sesuai dengan pekerjaan itu. Penempatan jabatan sesuai dengan kualifikasi pengetahuan, keahlian dan sikap mental yang mengacu pada persyaratan yang ditentukan. Sumber daya manusia yang bisa menjalankan berbagai tugas dan fungsinya akan menghasilkan kinerja lembaga yang memberikan manfaat bagi organisasi kerja, masyarakat dan individu tersebut. Fungsi manajemen sumber daya yang khusus mendatangkan calon pegawai untuk selanjutnya diseleksi yang paling baik dan sesuai dengan kriteria persyaratan salah satunya melalui rekrutmen. Semua hal di atas menjadi tugas dan tanggung jawab utama dari bidang sumber daya manusia ${ }^{2}$.

Pelaksanaan rekrutmen pegawai di Madrasah Aliyah Negeri 2 Sumedang dilakukan melalui perangkat manual brosur dan Online tidak bekerja sama dengan lembaga penyelenggara jasa informasi seperti koran ataupun dinas tenaga kerja. Perangkat kelengkapan rekrutmen di Madrasah Aliyah Negeri 2 Sumedang berupa standar operasional prosedur. Kurang informatifnya bidang humas di Madrasah Aliyah Negeri 2 Sumedang ketika melaksanakan open rekrutmen pegawai sehingga para pencari kerja kurang begitu mengetahui informasi rekrutmen. Dalam rekrutmen Madrasah Aliyah Negeri 2 Sumedang lebih mengutamakan jejaring alumni internal

\footnotetext{
${ }_{1}$ Abdul Hakim, Dinamika Manajemen Sumber Daya Manusia Dalam Organisasi (Pendekatan Konvensional Dan Nilai-Nilai Islami), Edisi I (Semarang: EF Press Digimedia, 2009), 28.

2 Tim Dosen Mata kuliah Manajemen Sumber Daya Manusia, Buku Ajar Manajemen Sumber Daya Manusia, Edisi I (Jakarta: Program Studi Teknik Industri Fakultas Teknik Universitas Wijaya Putra, 2009), 44.
} 
dari siswa-siswa Madrasah Aliyah Negeri 2 Sumedang yang telah lulus perguruan tinggi dan memenuhi kualifikasi pemenuhan tenaga kerja di Madrasah Aliyah Negeri 2 Sumedang $^{3}$.

Rekrutmen adalah serangkaian kegiatan untuk mencari dan mendatangkan pelamar kerja sesuai dengan motivasi, kemampuan, keahlian dan pengetahuan yang dibutuhkan untuk menutupi kekurangan yang diidentifikasi dalam proses perencanaan kepegawaian. Tujuan dari hal tersebut yaitu untuk memberikan efektivitas pada organisasi satuan kerja. Rekrutmen dilaksanakan untuk pengadaan pegawai baru ke dalam satuan kerja yang dalam kegiatannya memiliki aktivitas yang tinggi. Proses rekrutmen juga membutuhkan adanya proses yang selektif, hal ini dilakukan untuk pemerataan pegawai sehingga kekuatan sumber daya manusia yang ada bisa menjadi seimbang ${ }^{4}$.

Sebagai output dari program perencanaan sumber daya manusia, didapat komposisi tenaga kerja yang dibutuhkan oleh lembaga untuk periode waktu perencanaan tertentu. Komposisi yang meliputi jumlah dan kualitas tenaga kerja yang dibutuhkan oleh lembaga didapat dari hasil analisis terhadap "supply" dan "demand" tenaga kerja yang dibutuhkan oleh lembaga untuk periode perencanaan. Sebuah kenyataan bahwa dalam suatu organisasi selalu terbuka kemungkinan untuk terjadinya berbagai lowongan dengan aneka ragam penyebabnya ${ }^{5}$. Berdasarkan uraian latar belakang masalah di atas, maka perlu adanya kajian mendalam terkait manajemen rekrutmen sumber daya manusia di MAN 2 Sumedang.

\section{KAJIAN PUSTAKA}

Rekrutmen didefinisikan sebagai sebuah keputusan tentang cara mencari calon tenaga kerja bertujuan untuk mendapatkan sebanyak-banyaknya calon tenaga kerja yang sesuai dengan kriteria yang dibutuhkan oleh lembaga. Upaya untuk mendapatkan calon tenaga kerja ini dimaksudkan agar lembaga dapat lebih leluasa untuk memilih pegawai agar didapat yang paling sesuai dengan persyaratan yang

${ }^{3}$ Kepala Tata Usaha, Laporan Wawancara Bersama Kepala Tata Usaba Madrasah Aliyah Negeri 2 Sumedang (Sumedang).

${ }^{4}$ Leli Sumanti Lubis and Nora Pitri Nainggolan, 'Proses Rekrutmen Dan Seleksi Terhadap Kinerja Karyawan Pada Pt Schneider Electric Manufacturing Batam', Jurnal Akuntansi, 2.1 (2018), 7677.

${ }^{5}$ Hakim, Dinamika Manajemen Sumber Daya Manusia..., 34-35. 
dibutuhkan oleh jabatannya. Proses pencocokan pegawai sifatnya dua arah dalam arti bahwa lembaga mencari pegawai yang paling cocok dengan kualifikasi jabatan dan tenaga kerja pun mencari pekerjaan yang sesuai dengan kebutuhan, bakat, minat dan kemampuannya ${ }^{6}$.

Rekrutmen merupakan proses menentukan dan menarik pelamar yang memiliki kemampuan untuk bekerja dalam sebuah lembaga. Pelaksanaan ini dimulai ketika ada formasi kekosongan jabatan di lembaga dan berakhir ketika berkas dokumen lamaran diserahkan ke lembaga bersangkutan. Hasilnya merupakan kumpulan pelamar calon pegawai baru untuk diseleksi dan dipilih. Rekrutmen juga dapat dikatakan sebagai suatu proses untuk mendapatkan jumlah pegawai yang berkualitas untuk menduduki suatu jabatan atau pekerjaan dalam lembaga?. Manajemen asal dari kata to manage yang artinya mengatur/mengelola. Pengaturan dilakukan melalui proses berdasarkan urutan dari fungsi-fungsi manajemen. Dengan demikian, manajemen merupakan suatu proses untuk mewujudkan tujuan yang diinginkan ${ }^{8}$.

Rekrutmen menurut Schermerhorn merupakan sebuah proses dalam menarik kandidat pegawai guna mengisi formasi posisi kerja yang kosong. Proses rekrutmen yang efektif akan memberikan peluang kerja pada orang yang mempunyai kemampuan dan keterampilan yang memenuhi kriteria serta spesifikasi dari pekerjaan'. Manajemen sumber daya manusia menurut Mondy dan Noe yaitu sebagai pendayagunaan sumber daya manusia untuk pencapaian tujuan lembaga. Manajemen sumber daya manusia yaitu sebuah proses perencanaan, proses pengorganisasian, proses pengarahan dan pengawasan kegiatan pengadaan, proses pengembangan, proses pemberian kompetensi, proses pengintegrasian, proses pemeliharaan dan

${ }^{6}$ Hakim, Dinamika Manajemen Sumber Daya Manusia..., 35.

7 Taufiqurokhman, Mengenal Manajemen Sumber Daya Manusia, ed. by Resta J, Edisi (Jakarta: Fakultas Ilmu Sosial dan Ilmu Politik Universitas, 2009), 54.

8 A. Rusdiana, Manajemen Operasi, ed. by Beni Ahmad Saebani, Edisi 1 (Bandung: CV Pustaka Setia, 2014), 17.

9 Masram and Mu'ah, Manajemen Sumber Daya Manusia Profesional, ed. by Hilya, Edisi I (Sidoarjo: Zifatama Publisher, 2017), 23-24. 
pelepasan sumber daya manusia agar tercapai tujuan dari organisasi, masyarakat dan individu ${ }^{10}$.

Apabila suatu lembaga berencana melaksanakan rekrutmen maka perekrutan itu memerlukan suatu proses. Melalui perencanaan sumber daya manusia dapat diketahui kesenjangan antara kebutuhan lembaga dan permintaan pegawai dengan ketersediaan calon pegawai, baik dari segi kuantitas, kualitas dan kualifikasi. Jika diketahui bahwa pegawai yang tersedia lebih kecil, maka yang dibutuhkan adalah pelaksanaan rekrutmen. Sebelum memutuskan untuk melaksanakan rekrutmen, lembaga perlu mempertimbangkan alternatif, misalnya meminta pegawai yang ada untuk bekerja lebih lama dari waktu kerja normal ${ }^{11}$ :

\section{METODE DAN PENDEKATAN PENELITIAN}

Pendekatan penelitian yang dipakai dalam penelitian ini yaitu pendekatan kualitatif dengan metode deskriptif, metode ini diartikan sebagai sebuah prosedur pemecahan masalah, diselidiki dengan menggambarkan keadaan objek yang diteliti berdasarkan fakta dan apa adanya ${ }^{12}$. Metode studi pustaka dilakukan dengan cara meneliti dokumen atau buku-buku serta teks lainnya yang berhubungan dengan rekrutmen pegawai di Madrasah Aliyah Negeri 2 Sumedang seperti buku kepegawaian, surat keterangan pengangkatan pegawai, brosur open rekrutmen pegawai dll. Sedangkan metode studi lapangan dengan cara mengamati pelaku pendidikan, fenomena, keberadaan dan perangkat kelengkapan rekrutmen.

Jenis data yang dikumpulkan adalah jenis data kualitatif, yang sifatnya deskriptif berupa kata-kata tertulis, lisan dari orang-orang, gejala-gejala, kejadian dan peristiwa yang dapat diamati yang berkaitan dengan rekrutmen pegawai di Madrasah Aliyah Negeri 2 Sumedang. Kata-kata serta tindakan orang yang dapat diamati atau diwawancarai yang dicatat melalui catatan lapangan atau rekaman dalam penelitian ini adalah sumber utama, dengan menggunakan teknik sampling, yaitu dengan mewawancarai kepada pihak kepala madrasah, kepala tata usaha, sebagai key informan,

10 Tim Dosen Mata kuliah Manajemen Sumber Daya Manusia, Buku Ajar Manajemen Sumber Daya Manusia, Edisi I (Jakarta: Program Studi Teknik Industri Fakultas Teknik Universitas Wijaya Putra, 2009), 01.

11 Malayu S.P Hasibuan, Manajemen Sumber Daya Manusia (Edisi Revisi), ed. by Eko Puji Sulistyo, Edisi I (Jakarta: CV. R.A.De.Rozarie, 2017), 39.

12 Lexy J. Moleong, Metode Penelitian Kualitatif (Bandung: Remaja Rosdakarya, 2004),14 
kemudian diikuti oleh snowball Process, yaitu sumber data berikutnya diperoleh dari key informan tersebut secara bergulir, dan akan dihentikan apabila terjadi pengulangan informasi.

Teknik wawancara yang digunakan adalah wawancara tidak restruktur, dilaksanakan dengan kepala madrasah, kepala tata usaha, dan wakil kepala madrasah bidang hubungan masyarakat. Teknik dokumentasi dengan mencari data dokumentasi tentang kelengkapan perangkat rekrutmen pegawai, faktor penghambat internal dan eksternal rekrutmen pegawai di Madrasah Aliyah Negeri 2 Sumedang. Teknik analisis data yang digunakan adalah teknik analisis data deskriptif kualitatif model interaktif ${ }^{13}$. Adapun tahapan langkah-langkah analis data meliputi: unitisasi, kategorisasi, reduksi, kodifikasi, dan penafsiran data.

\section{HASIL DAN PEMBAHASAN}

\section{Standar Operasional Prosedur Rekrutmen MAN 2 Sumedang}

SOP Rekrutmen dan Seleksi Kependidikan ini disusun dalam rangka memenuhi kebutuhan tenaga kependidikan di lingkungan Universitas Gunadarma. Pengadaan tenaga kependidikan dimulai dari proses seleksi penerimaan sampai dengan keputusan penerimaan tenaga kependidikan serta penempatannya di Madrasah Aliyah Negeri 2 Sumedang. SOP ini mencakup mekanisme rekrutmen kependidikan mulai dari proses analisis kebutuhan tenaga kependidikan sampai dengan pengangkatan tenaga kependidikan. SOP ini diharapkan dapat memandu pihak-pihak yang terkait dengan rekrutmen, seleksi dan penempatan tenaga kependidikan.

Persyaratan dokumen yang harus tersedia sebelum masuk dalam SOP ini adalah:

1. Dokumen lamaran tenaga kependidikan

2. Dokumen form wawancara

3. Soal test TPA dan Bahasa Inggris

4. Dokumen/Sarana test pemeriksaan kesehatan \& test Psikologi

5. Dokumen Hasil pemeriksaan kesehatan

${ }^{13}$ Milles, Matthew B \& Huberman, Michael A., Analisis Data Kualitatif (Jakarta: Universitas Indonesia (UI-Press), 1992), 20) 
6. Dokumen Surat Tugas/Surat Keputusan Pengangkatan tenaga Kependidikan

Secara umum tugas seorang tenaga Kependidikan berkaitan dengan tugas administratif dan keahlian khusus yang mendukung proses belajar mengajar. Oleh karena itu persyaratan umum tenaga pendukung akademik meliputi:

1. Beriman dan bertaqwa kepada Tuhan Yang Maha Esa

2. Berwawasan Pancasila dan Undang-Undang Dasar 1945

3. Lulus dari jenjang pendidikan SMA, D3, S1 ke atas

a. Tenaga kependidikan memiliki kualifikasi akademik paling rendah lulusan program diploma 3 (tiga) yang dinyatakan dengan ijazah sesuai dengan kualifikasi tugas pokok dan fungsinya.

b. Tenaga administrasi memiliki kualifikasi akademik paling rendah SMA atau sederajat.

c. Tenaga kependidikan yang memerlukan keahlian khusus wajib memiliki sertifikat kompetensi sesuai dengan bidang tugas dan keahliannya.

4. Memahami minimal satu bahasa asing (minimal secara pasif)

5. Sehat jasmani dan rohani

6. Memiliki kemampuan untuk menyelenggarakan pendidikan dalam rangka pemenuhan capaian pembelajaran lulusan.

7. Mempunyai moral dan integritas yang tinggi

8. Memiliki rasa tanggung jawab yang besar terhadap masa depan bangsa dan negara

\section{Perangkat kelengkapan rekrutmen pegawai di MAN 2 Sumedang}

Perangkat rekrutmen di madrasah aliyah negeri 2 Sumedang menggunakan media iklan sosial media dengan memakai pamflet Online. Forum media yang di informasikan yaitu perguruan tinggi untuk menyasar fresh graduate. Selain itu jejarang yang digunakan oleh madrasah dalam pelaksanaan open rekrutmen adalah jejaring alumni madrasah aliyah negeri 2 sumedang yang memiliki kualifikasi dan keahlian di bidang yang sedang dicari pelamarnya. Group Facebook dan Whatts Apps alumni menjadi media komunikasi dan informasi bagi lembaga dalam menginformasikan rekrutmen. Untuk media berbayar lainnya madrasah masih belum menggunakan karena dirasa masih dapat dilakukan di ruang lingkup internal jejaring madrasah. 
Sehingga pegawai yang terjaring dari alumni lebih mengetahui situasi kondisi lingkungan internal lembaga pendidikan di madrasah aliyah negeri 2 sumedang $^{14}$.

Selain itu pula madrasah mempertimbangkan rekomendasi dari para stake holder madrasah seperti komite dalam menerima rekrutmen pegawai. Rekomendasi tersebut di sampaikan kepada kepala madrasah dan diproses hingga menghasilkan keputusan akhir yaitu penerimaan atau penolakan calon pegawai tersebut. Calon rekomendasi pegawai tersebut dilihat dari kriteria, skill dan sumbangsih pengabdian terhadap lembaga. Media ini digunakan ketika ada rekomendasi dari komite, akan tetapi jalur normatif melalui media rekrutmen iklan dan organisasi tetap di tempuh oleh madrasah sebagai prosedural dalam menjalankan standar operasional prosedur yang di miliki oleh madrasah aliyah negeri 2 sumedang $^{15}$.

Dalam buku A.Rusdiana dijelaskan media-media yang dapat digunakan dalam kelengkapan rekrutmen pegawai yaitu memanfaatkan media iklan baik dari elektronik maupun media cetak yang memiliki efektivitas tinggi dalam menjaring pegawai. Hal tersebut memiliki banyak keuntungan antara lain organisasi mempunyai kesempatan yang lebih luas untuk memilih calon pegawai. Selanjutnya sedana dengan teori bahwa ada rekomendasi dari pegawai lainnya atau dalam ruang lingkup madrasah adalah komite sebagai pertimbangan calon pegawai. Para karyawan yang sedang bekerja bisa merekomendasikan calon karyawan baru dalam organisasinya. Dengan sendirinya kemampuan karyawan yang direkomendasikan tersebut sesuai dengan kemampuan yang diperlukan oleh organisasi. Selanjutnya dari lembaga-lembaga pendidikan lain seperti perguruan tinggi, di sebelah gedung MAN 2 Sumedang berdekatan dengan perguruan tinggi 11 april yang memiliki fakultas ilmu pendidikan ${ }^{16}$.

\section{Pendukung Internal Rekrutmen Pegawai Di MAN 2 Sumedang}

Karakteristik Organisasional di madrasah yang sangat kental dengan nuansa religi islami sangat bagus menarik pelamar dari perguruan tinggi islam. Karakteristik organisasional di MAN 2 Sumedang sangat mempengaruhi desain dan implementasi sistem rekrutmen yaitu dengan secara islami dan modern, lebih simpel dalam prosesi

${ }^{14}$ Kepala Madrasah, Laporan Rekap Mekanisme Rekrutmen Pegawai MAN 2 Sumedang (Sumedang, 2017).

15 Komite Madrasah, Laporan Wawancara Bersama Komite Madrasah Aliyah Negeri 2 Sumedang (Sumedang).

16 A. Rusdiana, Manajemen Sumber Daya Manusia Untuk Meraib Keunggulan Kompetitif, II (Bandung: Arsad Press, 2013), 49-50. 
rekrutmen pegawai. Organisasi lain yang kurang memperhatikan Citra lembaganya dalam promosi dari dalam hierarki hanya bergantung pada iklan, penggunaan agen tenaga kerja, dan perekrutan dari kampus sehingga kurang efisien dalam pendanaan rekrutmen.

Citra Madrasah Aliyah Negeri 2 Sumedang yang sangat baik dengan berbagai torehan prestasi ditambah dengan pengelolaan madrasah yang tertata dengan baik menjadi salah satu daya tarik kelembagaan bagi para pelamar kerja. Poin tersebut menjadi salah satu daya jual dari lembaga kepada para pencari kerja khususnya ketika pelaksanaan open rekrutmen sehingga tanpa terlalu banyak promosi iklan pun para pelamar sudah banyak yang berdatangan ${ }^{17}$. Senada dengan teori bahwa citra organisasi yang positif ataupun negatif, buruk ataupun baik, akan mempengaruhi persepsi pelamar kerja.

Kebijakan organisasional kepala madrasah adalah ketentuan umum yang memberikan kerangka acuan bagi pengambilan ke putusan internal lembaga pendidikan madrasah. Kebijakan rekrutmen organisasi juga mengarahkan kepada kepala madrasah sebagai pimpinan tertinggi bersama dengan komite dan wakil kepala madrasah lainnya dalam membuat keputusan penarikan. Jadi wujudnya dapat berupa pedoman tertulis seperti surat keterangan, surat keputusan, surat pengesahan, surat edaran, surat panggilan, dll maupun tidak tertulis seperti keputusan lisan yang sebelumnya telah dimusyawarahkan bersama seluruh civitas akademik Madrasah Aliyah Negeri 2 Sumedang.

\section{Kendala Eksternal Rekrutmen Pegawai Di MAN 2 Sumedang}

Persyaratan pekerjaan yang sangat ketat dalam administrasi di madrasah aliyah negeri dengan prosedur yang lumayan panjang menjadikan salah satu kendala keluhan dari para calon pegawai. Sistem rekrut yang masih manual dan belum menggunakan Online pun menjadikan pemenuhan berkas perlu di kolektif dan dikumpulkan langsung ke sekretariat kantor penerimaan pegawai baru ${ }^{18}$. Hal tersebut senada dengan teori bila persyaratan suatu pekerjaan sangat sulit bagi tenaga pelamar akan

\footnotetext{
17 Ma'mun Khoer, Laporan Wawancara Bersama Kepala Madrasah Aliyah Negeri 2 Sumedang (Sumedang, 2019).

18 Kepala Tata Usaha, Laporan wawancara dengan kepala TU Madrasah Aliyah Negeri 2 Sumedang.
} 
mempengaruhi tingkat keinginan mereka untuk untuk melamar pada organisasi yang bersangkutan.

Kebijakan promosi dari dalam madrasah menjadikan pelamar dari luar sangat sulit untuk masuk ke dalam formasi, sehingga terkadang ada juga kesenjangan antara linieritas pekerjaan dengan para pencari kerja yang memenuhi syarat secara administratif. Jika keduanya memiliki kriteria kelengkapan berkas administratif yang sama maka yang akan lolos adalah pelamar dari alumni Madrasah Aliyah Negeri 2 Sumedang dan jika calon tenaga kerja dari dalam tidak sesuai maka pengisian lowongan kerja akan tertunda. Selain itu membatasi jumlah pelamar potensial dari luar yang ingin masuk ke dalam madrasah ${ }^{19}$.

Kebijakan kompensasi atau gaji yang minim pula menjadikan rekrutmen agak sulit, karena pemenuhan gaji yang kurang sesuai kurang diminati oleh para pelamar hal tersebut yang menjadikan pelamar enggan untuk masuk dan bertahan selama mungkin sampai adanya formasi pengangkatan. Perekrut jarang mempunyai otoritas untuk melebihi kisaran gaji yang sudah dipatok madrasah sehingga gaji yang mengatur adalah internal madrasah dan pegawai hanya mengikuti kebijakan yang ada.

\section{KESIMPULAN}

Pertama, Perangkat rekrutmen di madrasah Aliyah Negeri 2 Sumedang menggunakan media iklan sosial media dengan memakai pamflet Online. Forum media yang di informasikan yaitu perguruan tinggi untuk menyasar fresh graduate. Kedua, karakteristik Organisasional di madrasah yang sangat kental dengan nuansa religi islami sangat bagus menarik pelamar dari perguruan tinggi islam, citra Madrasah Aliyah Negeri 2 Sumedang yang sangat baik dengan berbagai torehan prestasi ditambah dengan pengelolaan madrasah yang tertata dengan baik menjadi salah satu daya tarik kelembagaan bagi para pelamar kerja. Ketiga, kebijakan kompensasi atau gaji yang minim pula menjadikan rekrutmen agak sulit, karena pemenuhan gaji yang kurang sesuai kurang diminati oleh para calon pegawai. Persyaratan pekerjaan yang sangat ketat dalam administrasi di madrasah aliyah negeri dengan prosedur yang lumayan panjang menjadikan salah satu kendala keluhan dari para calon pegawai.

${ }^{19}$ Komite Madrasah, Laporan wawancara bersama komite Madrasah Aliyah Negeri 2 Sumedang. 


\section{DAFTAR PUSTAKA}

Hakim, Abdul, Dinamika Manajemen Sumber Daya Manusia Dalam Organisasi (Pendekatan Konvensional Dan Nilai-Nilai Islami), Edisi I (Semarang: EF Press Digimedia, 2009)

Kepala Tata Usaha, Laporan Wawancara Bersama Kepala Tata Usaha Madrasah Aliyah Negeri 2 Sumedang (Sumedang)

Khoer, Ma'mun, Laporan Wawancara Bersama Kepala Madrasah Aliyah Negeri 2 Sumedang (Sumedang, 2019)

Komite Madrasah, Laporan Wawancara Bersama Komite Madrasah Aliyah Negeri 2 Sumedang (Sumedang)

Lexy J. Moleong, Metode Penelitian Kualitatif (Bandung: Remaja Rosdakarya, 2004)

Madrasah, Kepala, Laporan Rekap Mekanisme Rekrutmen Pegawai MAN 2 Sumedang (Sumedang, 2017)

Masram, and Mu'ah, Manajemen Sumber Daya Manusia Profesional, ed. by Hilya, Edisi I (Sidoarjo: Zifatama Publisher, 2017)

Milles, Matthew B \& Huberman, Michael A., Analisis Data Kualitatif (Jakarta: Universitas Indonesia (UI-Press), 1992)

Poltak Sinabela, Lijan, Manajemen Sumber Daya Manusia, Edisi III (Jakarta: Bumi Aksara, 2018)

Rusdiana, A., Manajemen Operasi, ed. by Beni Ahmad Saebani, Edisi 1 (Bandung: CV Pustaka Setia, 2014)

_-, Manajemen Sumber Daya Manusia Untuk Meraib Keunggulan Kompetitif, II (Bandung: Arsad Press, 2013)

S.P Hasibuan, Malayu, Manajemen Sumber Daya Manusia (Edisi Revisi), ed. by Eko Puji Sulistyo, Edisi I Jakarta: CV. R.A.De.Rozarie, 2017) $<$ https://doi.org/10.1103/PhysRevC.84.054003>

Sugiyono, Metode Penelitian Kuantitatif, Kualitatif Dan R\&D, 24th edn (Bandung: Alfabeta, 2016)

Suharsimi Arikunto, Prosedur Penelitian Suatu Pendekatan Praktek (Jakarta: PT. Rineka Cipta, 2002)

Sumanti Lubis, 'Proses Rekrutmen Dan Seleksi Terhadap Kinerja Karyawan Pada Pt Schneider Electric Manufacturing Batam', Jurnal Akuntansi Barelang, 2 (2018), danra(76--88) <http://ejournal.upbatam.ac.id/index.php/jab/article/ view/256>

Taufiqurokhman, Mengenal Manajemen Sumber Daya Manusia, ed. by Resta J, Edisi (Jakarta: Fakultas Ilmu Sosial dan Ilmu Politik Universitas, 2009)

Tim Dosen Mata kuliah Manajemen Sumber Daya Manusia, Buku Ajar Manajemen Sumber Daya Manusia, Edisi I (Jakarta: Program Studi Teknik Industri Fakultas Teknik Universitas Wijaya Putra, 2009) <http://library.uwp.ac.id/ digilib/files/disk1/1/--timpengaja-26-1-teknikp-s.pdf> 